\title{
Flutuação populacional de curculionídeos-das-raízes em citros
}

\author{
Population dynamics of root weevils in citrus
}

\author{
Jerson Vanderlei Carús Guedes ${ }^{\mathrm{I}}$ José Roberto Postali Parra
}

\begin{abstract}
- NOTA -
RESUMO

O objetivo neste trabalho foi estudar a flutuação populacional de curculionídeos-das-raízes em citros. Foram feitas amostragens quinzenais das fases de larva, de pupa e adulta, em laranjeiras de quatro fazendas, em Itapetininga, São Paulo, de março de 2000 a fevereiro de 2002. A emergência dos adultos foi quantificada em gaiolas sob a copa das plantas e a população de adultos, na copa das plantas, com pano-debatida; as larvas e pupas em trincheiras abertas no solo, sob a copa das plantas. Com base na flutuação populacional das fases, é possível afirmar que os insetos são univoltinos. A maioria dos adultos emergiu de outubro a abril, com picos no início do período. Foram encontradas as espécies Parapantomorus fluctuosus (Boheman), Naupactus cervinus Boheman $e$ Naupactus versatilis Hustache, sendo as duas últimas as mais

March, 2000 and February, 2002. The emergence of adults was evaluated in cages under plant canopy and the adult population at plant canopy with a beating cloth; larvae and the pupae in ditches opened in the soil, under plant crowns. Based on the population dynamics, the insects are univoltine. Most adults emerged from October to April, with peaks at the beginning of the period. Species Parapantomorus fluctuosus (Boheman), Naupactus cervinus Boheman and Naupactus versatilis Hustache were more frequent in Itapetininga, SP, although the peaks and times were different. Larvae occurred almost during the whole year, with population peaks from June to January. The number of curculionids was lower in the second year of the study for all insect phases, probably due to drought. Adults and larvae sampled, with beating cloths and in cages, could be used to detect, quantify and predict the occurrence of citrus root weevils.
\end{abstract} freqüentes, embora com picos em épocas diferentes. Ocorreram larvas praticamente o ano inteiro, com picos populacionais no período de junho a janeiro. A população de curculionídeos foi menor no segundo ano de estudo, provavelmente em conseqüencia da estiagem. Dentre as fases estudadas, os adultos $e$ as larvas, amostrados com pano-de-batida e em trincheiras no solo, podem servir para detecção, quantificação e previsão da ocorrência dos curculionídeos-das-raízes dos citros.

Palavras-chave: Naupactus cervinus, Naupactus versatilis, Curculionidae, Naupactini.

\section{ABSTRACT}

The goal of this study was to evaluate the population dynamics of citrus root weevils. Samples of the larval, pupa and adult phases were taken every 15 days in four citrus farms in Itapetininga, State of São Paulo, Brazil, between
Key words: Naupactus cervinus, Naupactus versatilis, Curculionidae, Naupactini.

A cultura dos citros apresenta grande importância para a economia brasileira, especialmente, para a Região Sudeste do Brasil, onde se encontra mais de $70 \%$ da área cultivada do país e, praticamente, todo o parque agroindustrial do setor (FNP CONSULTORIA E COMÉRCIO, 2006). Dentre os problemas fitossanitários dos citros, os curculionídeos-das-raízes têm sido considerados pragas secundárias, embora em algumas regiões dos Estados de São Paulo e de Minas Gerais, sejam consideradas pragas primárias da cultura,

'Departamento de Defesa Fitossanitária, Centro de Ciências Rurais (CCR), Universidade Federal de Santa Maria (UFSM), 97105900, Santa Maria, RS, Brasil. E-mail: jerson.guedes@smail.ufsm.br. Autor para correspondência.

"Departamento de Entomologia, Fitopatologia e Zoologia Agrícola, Escola Superior de Agricultura Luiz de Queiroz (ESALQ), Universidade de São Paulo (USP), Piracicaba, SP, Brasil. 
tanto pelos danos diretos causados pelas larvas às raízes das plantas, quanto pelos ferimentos que facilitam a instalação de patógenos, como Phytophthora spp., causador da gomose dos citros (GUEDES et al., 2002). Os adultos ocorrem praticamente o ano inteiro, mas as maiores populações são observadas entre setembro e maio. As fêmeas ovipositam sob o cálice dos frutos, nas quais as larvas eclodem, em seguida, caem e se desenvolvem no solo, sendo verificadas ano inteiro. Consomem radicelas, raízes finas e a casca das raízes mais grossas. Apesar dessas observações biológicas, muitos aspectos relacionados à ecologia desse grupo foram pouco estudados ou são ainda desconhecidos. Neste trabalho, o objetivo foi estudar a flutuação populacional das fases de larva, de pupa e adulto dos curculionídeos-das-raízes.

Foram feitas amostragens das fases de larva, de pupa e adulto de curculionídeos-das-raízes dos citros, em quatro fazendas (Campo de Aviação, Vaca Morta, Olho d’Água e Velha) da Empresa Citrovita, em Itapetininga, SP, de março de 2000 a fevereiro de 2002. Os dados meteorológicos foram coletados na Fazenda Umuarama, contígua a outras áreas experimentais. As fazendas apresentavam laranjeiras de 11 e 12 anos de idade das cultivares: Fazenda Campo de aviação - cv. 'Pêra', Fazenda Vaca Morta - cv. 'Natal' Fazenda Olho d'Água - cv. 'Pêra' e Fazenda Velha - cv. 'Natal'. Em cada fazenda, foi selecionada uma área de 0,7 a 1,0ha, conduzidas com tratos culturais recomendados, exceto o controle de ácaros e insetos que não foi realizado. As amostragens de insetos foram feitas em plantas ao acaso, quinzenalmente.

A flutuação populacional de adultos foi feita com dez gaiolas dispostas sob a copa e sobre o solo de plantas escolhidas ao acaso, em que foi contabilizada a emergência de adultos dos curculionídeos. As gaiolas foram confeccionadas com as laterais de madeira e tela anti-afídeos, mediam 4,0 x 4,0m, com 0,1m de altura. A cada seis meses, as gaiolas foram trocadas de planta. A flutuação populacional dos adultos, presentes na copa das plantas, foi efetuado utilizando-se um pano-debatida (4,0 x 4,0m), que era introduzido sob a copa e essas vigorosamente chacoalhadas, procedendo-se a contagem e identificação das espécies dos curculionídeos sobre o pano.

Foi realizada a análise de correlação entre o número médio de adultos que emergiram nas gaiolas com as condições de precipitação pluviométrica e temperatura do ar, daquele mês e do mês anterior à coleta pelo uso do teste $\mathrm{t}$ a $5 \%$ de probabilidade de erro. A flutuação populacional de larvas e pupas foi feita pela inspeção e contagem do número de insetos presentes no solo retirado e peneirado de uma trincheira
$(0,15 \times 2,0 \times 0,30 m$ de largura, comprimento e profundidade, respectivamente), medindo $0,3 \mathrm{~m}^{2}$, feita sob a copa da planta, do tronco até a linha de projeção da copa, aproximadamente.

Em cada fazenda, foi vistoriado o solo de dez trincheiras (plantas), escolhidas ao acaso. Para essas fases, dada a impossibilidade de separar os insetos por espécie, esles foram considerados como Naupactini ou curculionídeos-das-raízes. Os dados resultantes das 48 amostragens quinzenais, nas quatro áreas, foram agrupados, mês a mês, para comporem as figuras de flutuação populacional das fases de larva, de pupa e adulto de curculionídeos-das-raízes dos citros.

Ocorreu variação da emergência de adultos dos curculionídeos-das-raízes entre os anos e fazendas estudadas. Todavia, independentemente do tamanho da população, os picos populacionais, geralmente, ocorreram de outubro a dezembro, emergindo a maior parte da população, até abril (Figura 1). De forma análoga, RIPA (1992) havia observado que a população de adultos de $\boldsymbol{N}$. xanthographus (Germar) apresenta dinâmica populacional similar, em diferentes locais, por anos consecutivos, em videiras, no Chile. No primeiro ano de amostragem, observou-se um maior intervalo sem emergência de adultos nas gaiolas, para $\boldsymbol{N}$. versatilis e $\boldsymbol{P}$. fluctuosus, que possivelmente esteja relacionado às baixas precipitações e reduzida umidade do solo, verificadas entre março e julho de 2000 (Figura 1), embora, não tenha havido correlação da emergência com a precipitação pluviométrica. Segundo LOIÁCONO \& MARVALDI (1994), o déficit hídrico no solo promove atraso no desenvolvimento larval, retardando a emergência de Naupactini.

Os picos de emergência de $N$. cervinus, de Naupactus versatilis Hustache e de P. fluctuosus, ocorreram, com maior freqüência, entre outubro e dezembro; no entanto, $N$. cervinus apresentou um pico populacional também em março de 2000, além de exibir as maiores populações nos dois anos e em todas as áreas estudadas, com picos de até sete insetos planta ${ }^{-1}$ mês ${ }^{-1}$. Esses fatos, aliados à coleta de $\boldsymbol{N}$. cervinus durante nove meses do ano, exceto no período de julho a setembro, pode ser uma indicação da maior adaptação da espécie às condições locais (Figura 1f), além do maior risco como praga. A época em que há uma maior concentração de adultos pode permitir o planejamento e a adoção das práticas de controle num período mais curto de tempo.

As espécies $N$. cervinus e $N$. versatilis foram predominantes em relação à espécie $\boldsymbol{P}$. fluctuosus e muito mais freqüentes do que a $N$. ambiguus, $N$. navicularis, $N$. tarsalis e T. nodicollis, espécies também 

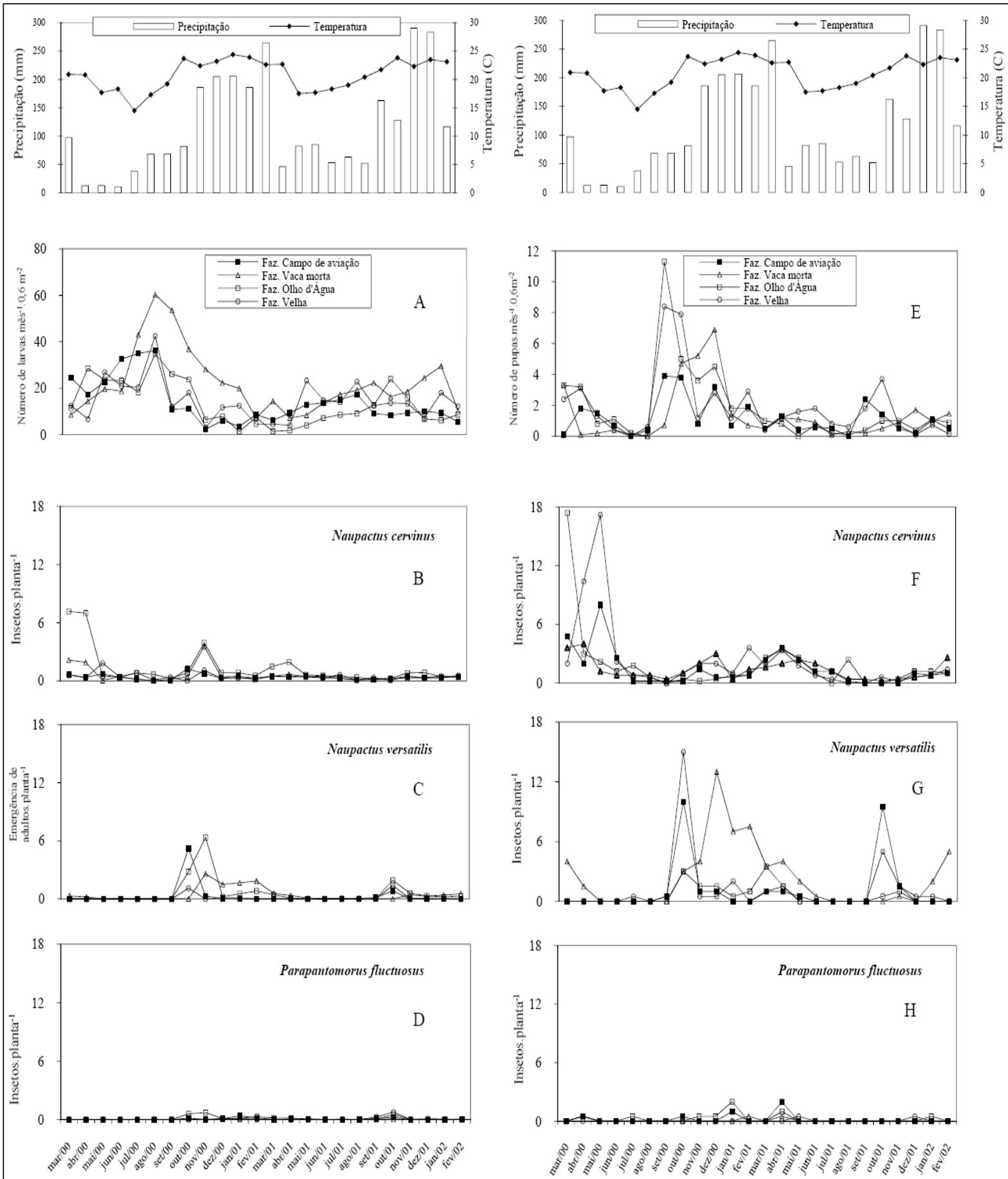

Figura 1 - Flutuação populacional de larvas (a), pupas (e), adultos dos curculionídeos-das-raízes nas gaiolas de emergência (bcd) e na copa das plantas (fgh), em quatro fazendas de citros, no Município de Itapetininga, SP, com a precipitação pluviométrica e temperatura média do período de 03/2000 a 02/2002.

observadas na área estudada. Entretanto, GUEDES et al. (2005), estudando a distribuição das espécies nos estados de São Paulo e Minas Gerais, constataram que P. fluctuosus ocorreu em localidades (23 municípios), seguida de $\boldsymbol{N}$. versatilis (14 municípios) e de $\boldsymbol{N}$. cervinus (seis municípios). A ocorrência de adultos dos curculionídeos-das-raízes na copa das laranjeiras, também variou entre os locais estudados nos dois anos 
de observação. As maiores populações foram observadas entre outubro e abril (Figura $1 \mathrm{f} \mathrm{e} \mathrm{1g).} \mathrm{As}$ três espécies apresentaram dinâmica populacional diferentes. No primeiro ano de observação, $N$. cervinus apresentou picos populacionais de adultos na copa, no período entre dezembro e abril enquanto, $\boldsymbol{N}$. versatilis foi no período entre outubro e fevereiro. Em alguns casos, os picos populacionais das espécies se sucederam no tempo, mantendo a população de adultos elevada, por períodos mais longos do que os picos de ocorrência, agravando o problema da praga (Figura $1 \mathrm{f}$ e 1g). De forma similar, LANTERI \& ARAGÓN (1994) observaram que populações de Atrichonotus taeniatulus (Berg), de Naupactus leucoloma Boheman e de Pantomorus auripes Hustache sucederam-se no tempo, como forma de maximizar o aproveitamento de recursos, na cultura da alfafa.

O número de adultos na copa somou, aproximadamente, 2,5 vezes maior do que a emergência de $\boldsymbol{N}$. cervinus e de $\boldsymbol{N}$. versatilis, sugerindo que, devido à longevidade dos curculionídeos, a mesma população foi contabilizada em duas ou mais amostragens, e que em campo, os insetos possivelmente vivam mais do que os 30 dias verificados para $\boldsymbol{N}$. cervinus e $\boldsymbol{N}$. versatilis, em laboratório (GUEDES et al., 2007). Por sua vez, a seca, verificada no primeiro ano de observação, resultou em efeitos mais severos sobre a população de $\boldsymbol{N}$. cervinus do que sobre a população de $N$. versatilis (Figura 1f e 1e), possivelmente, em decorrência da coincidência da emergência com o período de maior restrição hídrica (Figura 1f). A ocorrência de picos de emergência e de adultos na copa, nos mesmos períodos, por anos seguidos, facilitam a adoção de práticas de controle dos adultos dos curculionídeosdas-raízes dos citros, nessas épocas. Nos dois anos do estudo, a população de adultos, observada na copa das plantas, ultrapassou os níveis de controle empiricamente adotados pelos produtores de citros (cinco a dez insetos planta-1).

A população de larvas dos Naupactini oscilou ao longo do período de estudo, sendo encontradas larvas, durante, praticamente, os 24 meses de avaliação, nas quatro fazendas estudadas, exceto na fazenda Olho d’Água, no período entre janeiro e março de 2001 (Figura 1a). De forma semelhante, DE JAGER et al. (1989) observaram a ocorrência de larvas de diferentes idades de $\boldsymbol{N}$. leucoloma, durante o ano todo, na África do Sul. No primeiro ano do estudo, o pico de larvas ocorreu em agosto, nos quatro locais avaliados. A fazenda Vaca Morta, apresentou as maiores populações de larvas $\left(60 / 0,6 \mathrm{~m}^{2}\right)$, correspondendo a 1250 larvas por planta, aproximadamente. No segundo ano do estudo, os picos de larvas foram menos evidentes, ocorrendo de junho a janeiro, nas áreas de estudo, com média abaixo de 30 larvas $0,6 \mathrm{~m}^{-2}$, portanto apresentando valores inferiores à metade da população do primeiro ano (Figura 1a). Nos dois anos de amostragem, na fazenda Vaca Morta, apresentaram-se as maiores populações de larvas e, na fazenda Olho d'Água, os menores, não sendo possível, no entanto, determinar a causa dessa variação, devido à diversidade de fatores envolvidos, tais como tipo de porta-enxerto e de copa, tipo de solo (Figura 1a). A população de pupas dos Naupactini variou ao longo dos dois anos de amostragem. Nos meses de junho, julho e agosto de 2000, praticamente não ocorreram pupas, nas quatro fazendas. A partir de setembro, no entanto, a população aumentou, atingindo entre quatro e 11 pupas por $0,6 \mathrm{~m}^{2}$, que corresponderia à populações de 82 a 225 pupas por planta. No segundo ano do estudo, os picos populacionais de pupas foram menores, ocorrendo de setembro a fevereiro, nas diferentes áreas avaliadas. Os valores médios mensais não atingiram quatro pupas $0,6 \mathrm{~m}^{-2}$, inferior aos valores do primeiro ano (Figura 1e).

De acordo com o levantamento populacional das diferentes fases do ciclo dos curculionídeos-das-raízes dos citros, esses são univoltinos, e com picos populacionais bem definidos para os diferentes estágios (Figuras 1bcd, 1a e 1e). O conhecimento da ocorrência das diferentes fases do ciclo dos curculionídeos-das-raízes, em uma determinada época, associada ao conhecimento da vulnerabilidade das diferentes fases e da adequação das técnicas de controle, permite programar, de forma mais eficiente e econômica, o manejo desse grupo de pragas. Os curculionídeos-das-raízes são univoltinos, com base na sua flutuação populacional e, para cada fase do ciclo biológico, os picos são verificados em períodos determinados, permitindo prever a sua ocorrência. A maior parte da população de adultos emerge, entre outubro e abril, já as larvas e pupas ocorrem praticamente o ano inteiro com picos populacionais no período de junho a janeiro; e outubro e dezembro, respectivamente.

\section{REFERÊNCIAS}

DE JAGER, J. et al. Some aspects of the biology of the whitefringed beetle, Graphognathus leucoloma (Coleoptera: Curculionidae), in the lower Orange River irrigation area of South Africa. Phytophylactica, v.21, p.259-263, 1989. 
FNP CONSUltoria E COMÉRCIO. Agrianual 2006: anuário da agricultura brasileira. São Paulo, 2006. 504p.

GUEDES, J.C. et al. Ocorrência de curculionídeos-das-raízes dos citros em São Paulo. Laranja, v.23, n.2, p.308-320, 2002.

GUEDES, J.C. et al. Chave de identificação, ocorrência e distribuição dos curculionídeos-das-raízes dos citros em São Paulo e Minas Gerais. Neotropical Entomology, v.34, p.577-584, 2005.

GUEDES, J.C. et al. Aspectos biológicos da fase adulta dos curculionídeos-das-raízes dos citros. Ciência Rural, v.37, n.2, p.304-307, 2007.
LANTERI, A.A.; ARAGÓN, J.R. Dinamica poblacional y metodos de control. In: LANTERI, A.A. (Ed.). Bases para el control integrado de los gorgojos de la alfalfa. La Plata: De la Campana Ediciones, 1994. Cap.4, p.57-70.

LOIÁCONO, M.S.; MARVALDI, A.E. Biologia y daños ocasionados. In: LANTERI, A. A. (Ed.). Bases para el control integrado de los gorgojos de la alfalfa. La Plata: De la Campana Ediciones, 1994. Cap.3, p.49-55.

RIPA, R.S. Burrito de los frutales Naupactus xanthographus (Germar). Chile: INIA, 1992. 74p. (Boletin Tecnico, 192). 